\title{
A REPRESENTAÇÃO DA POBREZA PELA MÍDIA ON-LINE
}

\author{
Valeria lensen Bortoluzzi \\ Centro Universitário Franciscano \\ Santa Maria, Rio Grande do Sul, Brasil
}

\author{
Glivia Guimarães Nunes ${ }^{* *}$ \\ Universidade Aberta do Brasil
}

\begin{abstract}
Resumo: O tema deste estudo é a representação linguístico-discursiva da pobreza pela mídia on-line. O trabalho tem o apoio teórico-metodológico da Análise Crítica do Discurso (FAIRCLOUGH, 2001) e o aporte teórico do sistema de transitividade da Gramática Sistêmico-Funcional (HALLIDAY; MATTHIESSEN, 2004). O corpus foi constituído de dez notícias publicadas entre os meses de maio e novembro de 2011, em edições on-line de renomados jornais brasileiros: Zero Hora, Correio do Povo, O Globo, O Estado de S.Paulo e Folha de S.Paulo. Selecionamos duas notícias de cada jornal e realizamos uma análise qualitativa, de cunho interpretativista. Inicialmente, identificamos como cada um dos periódicos representa a pobreza para, em seguida, observar que representação a mídia on-line tem acerca da pobreza. Verificamos a existência de três representações para a pobreza: como um objeto à mercê das ações humanas, como uma entidade que age sobre os indivíduos e como uma situação enfrentada por muitas pessoas.
\end{abstract}

Palavras-chave: Texto. Discurso. Mídia on-line. Representação. Pobreza.

\section{INTRODUÇÃO}

Este artigo de pesquisa é um recorte de um estudo que desenvolvemos recentemente, por meio do qual buscamos investigar como a pobreza é representada linguístico-discursivamente pela mídia on-line. Entendemos a pobreza como um gravíssimo problema econômico e social que atinge e preocupa o mundo todo. Muitas pessoas são submetidas às suas severas consequências, sendo expostas a condições desumanas, carecendo de recursos básicos e essenciais para a sobrevivência. A pobreza é uma questão de extrema relevância, pois faz parte da vida de todos, do nosso cotidiano, inclusive do contexto escolar e, por isso, é muito importante que seja tematizada. Acreditamos que este trabalho possa fornecer contribuições pertinentes àqueles que vivenciam a pobreza e lutam contra ela.

O nosso estudo tem o embasamento teórico da Análise Crítica do Discurso (FAIRCLOUGH, 2001), que investiga como a desigualdade social é expressa no discurso. Atrelada a essa abordagem, está a Linguística Sistêmico-Funcional

\footnotetext{
* Doutora em Letras - Estudos Linguísticos. Email: valeria.bortoluzzi@gmail.com.

${ }^{* *}$ Mestre em Letras pela Universidade Federal de Santa Maria (UFSM). Tutora na Universidade Aberta do Brasil (UAB). Email: gliviagn@gmail.com.
} 
(HALLIDAY; MATTHIESSEN, 2004), com foco na concepção de oração como representação, no sistema de transitividade.

Este estudo foi desenvolvido a partir de uma análise qualitativa, de cunho interpretativo, de dez notícias. Escolhemos investigar como a pobreza é representada linguístico-discursivamente por cinco renomados jornais brasileiros, a saber: Correio do Povo, Zero Hora, O Estado de S.Paulo (popularmente conhecido como Estadão), Folha de S.Paulo e O Globo. Além disso, almejamos verificar quais os tipos de processos e, consequentemente, os tipos de orações com o item lexical "pobreza" (e termos de mesmo campo semântico) mais frequentes; investigar como se organizam, nas notícias, os aspectos textuais focalizados pela Análise Crítica do Discurso; e, por fim, como a mídia on-line representa a pobreza.

Optamos pela análise do discurso das mídias, mais especificamente de notícias disponibilizadas em jornais on-line, pois sabemos que a mídia exerce forte influência sobre a sociedade. Além disso, o discurso jornalístico tem um importante papel, já que possui as capacidades de formação e propagação de opiniões e ideologias, considerando que as representações em textos midiáticos podem funcionar ideologicamente, tendo em vista a colaboração na reprodução de relações sociais de dominação e exploração. Para Fairclough (1995, p. 12), "o trabalho ideológico da linguagem da mídia inclui formas particulares de representação do mundo [...], construções particulares de identidades sociais [...] e construções particulares de relações sociais ${ }^{1} "$.

É importante destacar que o conceito de ideologia é fundamental para a ACD. Fairclough (2001, p. 117) explica que "as ideologias são significações/construções da realidade [...] que são construídas em várias dimensões das formas/sentidos das práticas discursivas e que contribuem para a produção, a reprodução ou a transformação das relações de dominação". Partindo da ideia de que o fator social influencia nas escolhas linguísticas, acreditamos que o repertório lexical dos textos permitiu que identificássemos como a pobreza é vista pelos jornais que publicaram as notícias analisadas.

\section{REFERENCIAL TEÓRICO}

Neste momento, apresentamos algumas reflexões acerca da Análise Crítica do Discurso e da Linguística Sistêmico-Funcional, abordagens que embasam teoricamente este trabalho. Além disso, abordamos a concepção de gênero adotada neste estudo.

\subsection{A ANÁLISE CRÍTICA DO DISCURSO}

A Análise Crítica do Discurso (doravante, ACD) originou-se em 1990 e teve como precursores Teun van Dijk, Norman Fairclough, Gunther Kress, Teo van Leeuwen e Ruth Wodak. A ACD consiste em uma abordagem teórico-metodológica

\footnotetext{
${ }^{1}[\ldots]$ the ideological work of media language includes particular ways of representing the world $[\ldots]$, particular constructions of social identities [...], and particular constructions of social relations [...].
} 
responsável por investigar as relações de descrição, poder e controle manifestadas na linguagem. Trata-se de uma abordagem interpretativa e explicativa, que se preocupa com questões sociais e com a relação texto/discurso ${ }^{2}$ e sociedade. A linguagem é entendida, no âmbito dessa abordagem, como um meio de dominação e força social e é caracterizada por sua importante função social.

A ACD investiga de que maneira o abuso do poder social, a dominância e a desigualdade são expressos através da linguagem, bem como "o modo como se lhes resiste, pelo texto e pela fala, no contexto social e político" (VAN DIJK, 2005, p. 19). É com base nessa investigação que, segundo o autor, os analistas críticos do discurso assumem explicitamente uma posição, buscando "compreender, expor e, em última análise, resistir à desigualdade social" (VAN DIJK, 2005, p. 19). Dessa forma, a ACD não se limita a apenas detalhar estruturas do discurso, mas procura descrevê-las considerando a interação social e, principalmente, a estrutura social. Mais detalhadamente, essa abordagem põe foco "nos modos como as estruturas do discurso põem em prática, confirmam, legitimam, reproduzem ou desafiam relações de poder e de dominância na sociedade" (VAN DIJK, 2005, p.20).

Em ACD, "a variação em tipos de discurso é inseparável de factores económicos e sociais” (PEDRO, 1997, p. 20), de modo que variações linguísticas revelam as diferenças sociais que provêm de sua origem. Com isso, ressaltamos a importância do contexto na abordagem crítica, considerando que a linguagem insere-se em diferentes contextos sociais e que o contexto em que os interactantes trocam significados tem caráter social, pois possibilita a compreensão desses participantes à medida que interagem socialmente. A partir dos elementos contextuais, os falantes/escritores escolhem os elementos que irão compor o seu texto.

Segundo Pedro (1997), na ACD, o texto é uma "dimensão fundamental" e o sujeito é um ator ideológico, na medida em que é construído por e constrói processos discursivos. Nessa abordagem, de acordo com Fairclough (2001, p. 109), o texto "é considerado como um conjunto de 'traços' do processo de produção, ou um conjunto de 'pistas' para o processo de interpretação" e, inclusive, compõe o que o autor denomina concepção tridimensional do discurso, que, segundo ele, consiste no fato de o discurso ser constituído não somente pelo texto (descrição), mas também pela prática discursiva e pela prática social (interpretação). Essa concepção tridimensional é resultado da busca de unir essas três tradições analíticas fundamentais à análise do discurso.

Ao esboçar essa concepção tridimensional do discurso, Fairclough (2001, p. 90) o situa na dimensão da prática social, esclarecendo que o discurso deve ser compreendido como "o uso da linguagem como forma de prática social". Assim, por meio do discurso, que é um modo de ação e representação, as pessoas agem sobre o mundo. Além disso, é importante destacar que os estudiosos da ACD procuram investigar e mostrar o papel do discurso na produção e na reprodução da dominação.

A dominação analisada pela ACD tem por resultado a desigualdade social, e são as elites, as instituições ou grupos que detêm o poder. Wodak (2004, p. 224) afirma que

\footnotetext{
2 Neste caso, assumimos tanto a materialidade discursiva, denominada texto, quanto as formas de conceber o mundo em significado, conceito de Fairclough (2001, p.90-1) para discurso.
} 
as pesquisas em ACD "se voltam especificamente para os discursos institucional, político, de gênero social, e da mídia (no sentido mais amplo), que materializam relações mais ou menos explícitas de luta e conflito".

\subsection{A LINGUÍSTICA SISTÊMICO-FUNCIONAL}

A ACD se vale da Linguística Sistêmico-Funcional (LSF), de Halliday e Matthiessen (2004), para explicar como a linguagem materializa os discursos. A LSF, abordagem que fundamenta a gramática sistêmico-funcional, estuda a linguagem em suas diversas funções e tem embasamento semântico, partindo dos contextos de cultura e de situação, pois considera que todo texto é influenciado pelo contexto em que é produzido.

O contexto de situação é "o ambiente imediato no qual o texto está de fato funcionando" (FUZER; CABRAL, 2010, p. 15). De acordo com a LSF, o contexto de situação é representado por um modelo conceitual formado por três variáveis: campo, relações e modo. O campo consiste em o que está acontecendo. A variável relações refere-se a quem são os participantes envolvidos na ação social, que tipo de relações são estabelecidas entre eles (se essas relações são hierárquicas ou não, se há maior ou menor proximidade entre os participantes, determinada, na maioria das vezes, pelas relações de poder) e quais os papéis sociais (os estatutos) que desempenham. Já o modo diz respeito à função da linguagem naquela situação, qual o seu papel e qual o veículo utilizado. $\mathrm{O}$ contexto de cultura, por sua vez, é formado por crenças e valores que permanecem em uma coletividade durante um período de tempo e possui mais estabilidade que o contexto de situação. No âmbito do contexto de cultura, estão os gêneros. Um agrupamento de pessoas que faz uso da linguagem com objetivos semelhantes acaba desenvolvendo gêneros mais comuns às situações de interação daquele agrupamento, sejam eles orais ou escritos.

É de suma importância, na abordagem sistêmico-funcional, a noção de registro, que consiste em "uma variação funcional da linguagem (HALLIDAY, 1978) — os modelos de instância do sistema inteiro associados com um tipo de contexto (um tipo de situação)" (HALLIDAY; MATTHIESSEN, 2004, p. 27). A linguagem, por sua vez, é concebida, em LSF, como um sistema sociossemiótico que tem por base a gramática. Além disso, é organizada em estratos (níveis) e caracterizada pela diversidade funcional. Esses estratos são: Semântica, Léxico-gramática e Fonologia/Grafologia. Cada um constitui um sistema e todos são envolvidos pelo contexto. A linguagem como sistema se materializa em orações.

A LSF reconhece três metafunções da linguagem: a ideacional, a interpessoal e a textual. A metafunção ideacional (foco deste estudo) trata da compreensão do meio; a interpessoal preocupa-se com a relação entre sujeitos; e a textual é responsável pela organização da informação. Essas metafunções materializam-se, respectivamente, pelas variáveis contextuais campo, relações e modo.

Na metafunção ideacional, a oração é vista como representação. Thompson (2004, p. 86) informa que "a partir da perspectiva experiencial (ideacional), a linguagem compreende um conjunto de recursos para se referir às entidades no mundo e às maneiras pelas quais essas entidades atuam ou se relacionam entre si”. Essa metafunção 
é subdivida em duas subfunções, a experiencial (analisa a oração - sistema de transitividade) e a lógica (analisa o complexo oracional- grupos lexicais e oracionais).

A unidade de análise da LSF é a oração; ao analisá-la, leva-se em conta o sistema de transitividade. De acordo com Halliday e Matthiessen (2004), o sistema de transitividade é o que descreve toda a oração e onde se manifestam os significados experienciais. A oração é constituída de processos (materiais, mentais relacionais, existenciais, comportamentais e verbais), participantes e eventuais circunstâncias, sendo classificada de acordo com o tipo de processo. Cada tipo de oração apresenta seus participantes específicos, conforme a Tabela 1.

\section{Tabela 1 - Tipos de processos e participantes}

\begin{tabular}{|l|l|l|}
\hline Tipos de processo & Significado da categoria & Participantes \\
\hline $\begin{array}{l}\text { Material } \\
\text { Transformativo } \\
\text { Criativo }\end{array}$ & Fazer & Ator \\
& Acontecer & $\begin{array}{l}\text { Meta } \\
\text { Escopo } \\
\text { Beneficiário } \\
\text { Atributo }\end{array}$ \\
\hline $\begin{array}{l}\text { Mental } \\
\text { Perceptivo } \\
\text { Cognitivo } \\
\text { Emotivo } \\
\text { Desiderativo }\end{array}$ & Perceber & Experienciador \\
Relacional & Pensar & Fenômeno \\
Intensivo & Sentir & \\
Possessivo & Desejar & \\
\hline Circunstancial & Caracterizar & $\begin{array}{l}\text { Portador } \\
\text { Atributo }\end{array}$ \\
\hline Comportamental & Identificar & $\begin{array}{l}\text { Identificado } \\
\text { Identificador }\end{array}$ \\
\hline Verbal & & Comportante \\
& & Comportamento \\
& Comportar-se & Dizente \\
& & Verbiagem \\
Receptor \\
Alvo
\end{tabular}

Fonte: Adaptado de Fuzer e Cabral (2010, p. 103), com base em Halliday e Matthiessen (2004)

Em todos os tipos de orações pode haver circunstâncias acompanhando os participantes e os processos. Essas circunstâncias atribuem significados à oração na medida em que apontam o contexto em que se realizam os processos. São representadas por grupos preposicionais ou por grupos adverbiais e são classificadas em Extensão (Distância, Duração e Frequência); Localização (Lugar e Tempo); Modo (Meio, Qualidade, Comparação e Grau); Causa (Razão, Propósito e Interesse/Representação); Contingência (Condição, Falta e Concessão); Acompanhamento (Comitativo e Aditivo); Papel (Estilo/Aparência e Produto); Assunto e Ângulo (Recurso e Ponto de vista). 
Fairclough (2001) defende que as orações são multifuncionais e combinam significados ideacionais, interpessoais e textuais; "as pessoas fazem escolhas sobre o modelo e a estrutura de suas orações que resultam em escolhas sobre o significado (e a construção) de identidades sociais, relações sociais e conhecimento e crença" (FAIRCLOUGH, 2001, p. 104). Sendo assim, é possível afirmar que, através das escolhas léxico-gramaticais, o locutor deixa pistas de sua ideologia e de como representa o mundo na sua escrita, como acontece com o discurso da mídia, analisado nesta pesquisa. Muitos usos da linguagem são ideológicos, pois, em determinadas circunstâncias, estabelecem ou mantêm relações de dominação.

Vários estudos da ACD se reportam à teoria de Halliday. Wodak (2004, p. 232) expõe que "compreender as premissas básicas da gramática hallidayana e sua abordagem à análise linguística é essencial para uma compreensão mais ampla da ACD". Fairclough (2001, p. 105) considera que "Halliday (1985) faz uma apresentação mais avançada de uma forma de gramática particularmente útil à análise do discurso".

\subsection{GÊNERO NOTÍCIA E SUA CONSTRUÇÃO SOCIAL}

Apesar de este trabalho ter viés sistêmico-funcional e de a LSF ter um conceito próprio de gênero, adotamos aqui a perspectiva sociorretórica (MARCUSCHI, 2008, p.153), tendo em vista que, no Brasil, esta teoria, juntamente com a perspectiva do interacionismo sociodiscursivo, é mais utilizada para definir os gêneros. Além disso, Fairclough (2001) se baseia no conceito de gênero do discurso de Bakhtin, segundo o qual "os gêneros são "tipos relativamente estáveis de enunciados" (BAKHTIN, 2003, p. 262). Para Bakhtin (2003), todo e qualquer enunciado está dentro de um determinado gênero, está inscrito nele, e os gêneros emergem da interação social. Em conformidade com este conceito, Bazerman (2006, p. 31) afirma que "gêneros são fatos sociais sobre os tipos de atos de fala que as pessoas podem realizar e sobre os modos como elas os realizam". Com isso, o autor explica que os gêneros integram processos de atividades organizadas socialmente, a fim de que as pessoas compreendam-se o suficiente para que possam interagir, compartilhando significados e cumprindo seus propósitos práticos.

Marcuschi (2005) considera o gênero uma prática sócio-histórica, que está fortemente relacionada com a vida cultural. Para o autor,

\footnotetext{
os gêneros textuais são fenômenos históricos, profundamente vinculados à vida cultural. Fruto de trabalho coletivo, os gêneros contribuem para ordenar e estabilizar as atividades comunicativas do dia-a-dia. São entidades sócio-discursivas e formas de ação social incontornáveis em qualquer situação comunicativa [...] (p. 19).
}

Além disso, o autor expõe que o fato de um determinado gênero surgir, situar-se e integrar-se à cultura em que se desenvolve está diretamente relacionado com a funcionalidade desse gênero. De acordo com Marcuschi, não nos comunicamos verbalmente senão por gêneros, que têm "características sócio-comunicativas definidas por conteúdos, propriedades funcionais, estilo e composição característica" (2005, p. 23). 
O gênero analisado neste estudo é a notícia. Segundo Lage (2002, p. 16), “a notícia se define, no jornalismo moderno, como 'o relato de uma série de fatos a partir do fato mais importante ou interessante; e de cada fato, a partir do aspecto mais importante ou interessante"'. Para o autor, na notícia não se trata da narração de fatos, mas sim da "exposição" desses fatos. Conforme Lage, a notícia é uma construção retórica referencial e tem caráter objetivo e axiomático; sua linguagem é clara e inquestionável. Além disso, tem retórica referencial, isto é, se reporta ao mundo objetivo, fora do processo comunicativo. A notícia é um gênero da esfera midiática e a linguagem midiática é um espaço de poder, caracterizada por uma aparente neutralidade, quando, na realidade, expressa os argumentos dos jornalistas e das instituições às quais estão vinculados.

Nesse sentido, é importante destacar o caráter ideológico das instituições jornalísticas, que, através da articulação de sua linguagem, constroem suas representações de vários elementos sociais, de modo que cada jornal irá noticiar diferentemente um fato, de acordo com sua ideologia. Wodak (2004, p.231) trata da linguagem da mídia de massa, que ela afirma ser "detalhadamente analisada como um espaço de poder, de lutas, e também como um espaço onde a linguagem é aparentemente transparente".

\section{METODOLOGIA}

Este estudo é de cunho qualitativo. O corpus de análise é constituído de dez notícias retiradas das edições on-line de cinco importantes jornais brasileiros: Zero Hora, Correio do Povo, O Estado de S.Paulo (Estadão), Folha de S.Paulo e O Globo. De cada jornal, selecionamos dois textos, publicados entre os meses de maio e novembro de 2011. O critério de seleção foi o fato de que as notícias tivessem a pobreza como tema central. Para nos referirmos às notícias, adotamos códigos, conforme sistematizado na Tabela 2.

\section{Tabela 2 - Constituição do corpus}

\begin{tabular}{|c|c|c|c|}
\hline \multirow[b]{2}{*}{ Código } & \multicolumn{3}{|l|}{ Referência do texto } \\
\hline & Título & Data & Jornal \\
\hline CP\#1 & Em cinco anos, 10 milhões de pessoas deixam a pobreza no Brasil & $15 / 09 / 2011$ & Correio do Povo \\
\hline $\mathrm{CP} \# 2$ & Pobreza no Brasil tem face negra e feminina, diz Dilma & $19 / 11 / 2011$ & Correio do Povo \\
\hline ZH\#1 & RS tem mais de 300 mil pessoas vivendo na extrema pobreza & $03 / 05 / 2011$ & Zero Hora \\
\hline ZH\#2 & $\begin{array}{l}\text { Número de pessoas abaixo da linha pobreza nos EUA bate recorde } \\
\text { ao passar de } 46 \text { milhões }\end{array}$ & $13 / 09 / 2011$ & Zero Hora \\
\hline ESP\#1 & Pobreza extrema atinge 1 em cada 15 pessoas nos EUA & $03 / 11 / 2011$ & O Estado de S. Paulo \\
\hline ESP\#2 & Quase um terço das crianças dos EUA são pobres, aponta Censo & $17 / 11 / 2011$ & O Estado de S. Paulo \\
\hline FSP\#1 & Brasil vai enfrentar pobreza com determinação, ressalta Dilma & $06 / 06 / 2011$ & Folha de S. Paulo \\
\hline FSP\#2 & Número de pobres na França salta para 8,2 milhões de pessoas & $30 / 08 / 2011$ & Folha de S. Paulo \\
\hline OGlobo\#1 & $\begin{array}{l}\text { Número de americanos vivendo abaixo da linha de pobreza bate } \\
\text { recorde }\end{array}$ & $13 / 09 / 2011$ & O Globo \\
\hline OGlobo\#2 & Brasil tem 5 milhões de pessoas em situação de pobreza & $02 / 11 / 2012$ & O Globo \\
\hline
\end{tabular}


O cerne deste estudo é a interpretação. O espaço de nossa análise é exclusivamente a dimensão textual das notícias; trata-se de uma análise linguísticodiscursiva, partindo da dimensão textual do modelo tridimensional de Fairclough (2001). Para tal, tivemos como aporte teórico a Gramática Sistêmico-Funcional (GSF) e a abordagem teórico-metodológica Análise Crítica do Discurso (ACD).

Da GSF, utilizamos como base para nossa análise o sistema de transitividade, analisando a oração quanto ao tipo de processo, aos participantes e às circunstâncias. A partir desse sistema, todos os fragmentos que continham a palavra-chave "pobreza" (e aquelas de mesmo campo semântico como pobre; pobres; taxa de empobrecimento; miséria; vulneráveis; nível de vulnerabilidade, de grande fragilidade) foram decompostos em orações, as quais foram divididas em: 1) processos, 2) participantes e 3) circunstância. Em seguida, foi feita a classificação dessas orações e a representação linguístico-discursiva da pobreza foi identificada pela recorrência desses componentes da oração.

Com base na ACD, realizamos a análise textual, que foi organizada nestes itens: vocabulário e gramática. A partir dessas abordagens, conseguimos interpretar os dados textuais e, assim, identificar como os jornais, a partir das notícias selecionadas, representam linguístico-discursivamente a pobreza.

\section{RESULTADOS}

\section{EDIÇÃO ON-LINE DO JORNAL CORREIO DO POVO}

Nas notícias retiradas da edição on-line do jornal Correio do Povo, identificamos vinte e oito orações referentes à pobreza. São elas: treze orações relacionais, seis orações verbais, sete orações materiais, uma oração mental e uma oração existencial.

Quanto a ocorrências de participantes e circunstâncias, a pobreza e os termos do mesmo campo semântico integram essas orações constituindo Verbiagem (6 ocorrências) em orações verbais; Portador (5 ocorrências), Atributo (4 ocorrências) e Identificador (2 ocorrências) em orações relacionais; Ator (4 ocorrências) e Meta (1 ocorrência) em orações materiais; Fenômeno (1 ocorrência) em oração mental; Existente (1 ocorrência) em oração existencial; e Circunstância em 4 orações.

Identificamos que, no jornal Correio do Povo, a pobreza é representada de três formas distintas. Predominantemente, ela é vista como um mal contra o qual a sociedade luta constantemente, algo que está sujeito às ações do homem, devido ao fato de 'pobreza' participar de orações na forma de Verbiagem, Atributo, Identificador, Meta e Fenômeno em $50 \%$ das ocorrências. Além disso, a pobreza é vista como uma entidade que age sobre a sociedade, afetando a vida das pessoas, já que verificamos que em $36 \%$ das orações 'pobreza' desempenha papéis de Ator, Portador e Existente. Por fim, como uma condição de miserabilidade em que muitos indivíduos se encontram ou já se encontraram, pois aparece como circunstância em 14\% das orações. Exemplos dessas três representações para a pobreza são apresentados na Tabela 3. 
Tabela 3 - Exemplos: jornal Correio do Povo

\begin{tabular}{|l|ll|l|}
\hline Representação & Exemplo & Dilma defendeu a necessidade de ações de combate à [pobreza]. & Notícia \\
\hline Objeto & Verbiagem & $\mathrm{CP} \# 2$ \\
\hline Entidade & Portador & {$[$ Pobreza] no Brasil tem face negra e feminina [...]. } & $\mathrm{CP} \# 2$ \\
\hline Situação & Circunstância & $\begin{array}{l}\text { Os programas sociais e o aumento real do salário mínimo tiraram da } \\
{[\text { pobreza] } 10 \text { milhões de pessoas. }}\end{array}$ & CP\#1 \\
\hline
\end{tabular}

\section{EDIÇÃO ON-LINE DO JORNAL ZERO HORA}

Nas notícias retiradas da edição on-line do jornal Zero Hora, verificamos quarenta e uma orações referentes à pobreza. São elas: quinze orações relacionais, doze orações materiais, sete orações verbais, seis orações comportamentais e uma oração mental. Predominam, portanto, orações relacionais.

Em relação às ocorrências de participantes e circunstâncias, a pobreza e os termos do mesmo campo semântico integram essas orações como Verbiagem (7 ocorrências) em orações verbais; Portador (4 ocorrências), Atributo (4 ocorrências), Identificador (3 ocorrências) e Identificado (1 ocorrência) em orações relacionais; Ator (5 ocorrências), Meta (4 ocorrências) e Beneficiário (1 ocorrência) em orações materiais; e Fenômeno (1 ocorrência) em oração mental. Como Circunstância, a pobreza participa dessas orações num total de 11 ocorrências.

O jornal Zero Hora, predominantemente, representa a pobreza como algo que está sujeito às ações dos homens, o que reflete o objetivo que a sociedade tem de extingui-la. Essa representação é obtida a partir dos papéis exercidos por 'pobreza' como Meta, Verbiagem, Atributo, Identificador, Beneficiário e Fenômeno em 49\% das ocorrências. Além disso, esse veículo representa a pobreza como uma situação em que muitas pessoas vivem, pois em $27 \%$ das ocorrências ela é classificada como circunstância. Com menos incidência (24\%), verificamos a representação da pobreza como uma entidade capaz de agir sobre a sociedade, submetendo as pessoas a condições de miserabilidade, por exercer funções de Portador, Identificado e Ator. Essas três representações são exemplificadas na Tabela 4.

Tabela 4 - Exemplos: jornal Zero Hora

\begin{tabular}{|l|ll|l|}
\hline Representação & Exemplo & Notícia \\
\hline Objeto & Verbiagem & $\begin{array}{l}\text { A ministra do MDS, Tereza Campello, reafirmou o compromisso com a } \\
\text { erradicação de extrema [pobreza] até 2014. }\end{array}$ & ZH\#1 \\
\hline Situação & Circunstância & Atualmente, um em cada seis americanos vive na [pobreza]. & ZH\#2 \\
\hline Entidade & Ator & Linha da [pobreza] reúne 8,6\% da população. & ZH\#1 \\
\hline
\end{tabular}

\section{EDIÇÃO ON-LINE DO JORNAL O ESTADO DE S.PAULO}

Nas notícias retiradas do jornal O Estado de S.Paulo, identificamos um total de sessenta e uma orações referentes à pobreza. São elas: trinta orações relacionais, 
dezessete orações materiais, nove orações verbais, quatro orações comportamentais e uma oração existencial. Dessa forma, predominam as orações relacionais.

Quanto às ocorrências de participantes e circunstâncias, 'pobreza' e termos do mesmo campo semântico integram essas orações na função de Meta ( 9 ocorrências) e Ator (7 ocorrências) em orações materiais; Identificado (6 ocorrências), Atributo (14 ocorrências), Portador (5 ocorrências) e Identificador (2 ocorrências) em orações relacionais; Verbiagem (7 ocorrências) em orações verbais; Existente (1 ocorrência) em orações existenciais; e 10 ocorrências como Circunstâncias.

No jornal O Estado de S.Paulo, a pobreza é vista predominantemente como algo sobre o qual a sociedade tende a agir, buscando erradicá-la. Tal representação resulta do alto nível de incidência 'pobreza' desempenhando papéis de Meta, Atributo, Identificador e Verbiagem, os quais somam 32 ocorrências, ou seja, 50\% dos papéis exercidos pela pobreza em orações das notícias desse veículo. O jornal ainda vê a pobreza como algo que afeta a vida pessoas, ou seja, que tem ação sobre elas em $34 \%$ das ocorrências, nas quais participa nas funções de Ator, Identificado, Portador e Existente. Além disso, a pobreza é vista como uma situação, uma condição à qual muitas pessoas são submetidas, quando aparece como circunstância, em 16\% das orações que integra. A Tabela 5 apresenta exemplos dessas representações.

Tabela 5 - Exemplos: jornal O Estado de S.Paulo

\begin{tabular}{|l|ll|l|}
\hline Representação & Exemplo & Quase um terço das crianças dos EUA são [pobres]. & Notícia \\
\hline Objeto & Atributo & Ator & ESP\#2 \\
\hline Entidade & Circunstância & $\begin{array}{l}{[. . .] \text { quase um terço das crianças vivem atualmente abaixo da linha }} \\
\text { oficial de [pobreza]. }\end{array}$ & ESP\#1 \\
\hline Situação & ESP\#2 \\
\hline
\end{tabular}

\section{EDIÇÃO ON-LINE DO JORNAL FOLHA DE S.PAULO}

Nas notícias retiradas da edição on-line do jornal Folha de S.Paulo, identificamos vinte e uma orações referentes à pobreza. São elas: dez orações materiais, seis orações verbais, quatro orações relacionais e uma oração comportamental. Predominam, portanto, ocorrências de orações materiais.

Em termos de participantes e circunstâncias, 'pobreza' e termos do mesmo campo semântico integram essas orações como Ator (5 ocorrências) e Meta (5 ocorrências) em orações materiais; Verbiagem (6 ocorrências) em orações verbais; Identificador (1 ocorrência), Identificado (1 ocorrência) e Portador (1 ocorrência) em orações relacionais; Comportante (1 ocorrência) em orações comportamentais; e, em apenas 1 ocorrência, como circunstância.

No jornal Folha de S.Paulo, predomina a representação da pobreza como um mal sobre o qual a sociedade tende a agir com o objetivo de exterminá-lo. Essa interpretação se justifica ao identificarmos que, em $56 \%$ das orações das notícias desse veículo, a pobreza participa exercendo papéis de Meta, Verbiagem e Identificador. Há, ainda, outras duas representações com menor incidência, como um ser que age sobre os indivíduos, afetando sua qualidade de vida (verificada em 39\% das ocorrências, nas 
quais 'pobreza' desempenha os papéis de Ator, Identificado, Portador e Comportante) e como uma situação em que muitas pessoas vivem, por integrar uma oração (o que equivale a $5 \%$ das ocorrências) na forma de circunstância. Essas representações são exemplificadas na Tabela 6 .

\section{Tabela 6 - Exemplos: jornal Folha de S.Paulo}

\begin{tabular}{|c|c|c|c|}
\hline Representação & Exemplo & & Notícia \\
\hline Objeto & Meta & Brasil vai enfrentar [pobreza] com determinação. & FSP\#1 \\
\hline Entidade & Ator & A [pobreza] afeta os desempregados. & FSP\#2 \\
\hline Situação & Circunstância & $13,5 \%$ da população da França estão "abaixo do teto da [pobreza]", [...]. & FSP\#2 \\
\hline
\end{tabular}

\section{EDIÇÃO ON-LINE DO JORNAL O GLOBO}

Nas notícias retiradas do jornal O Globo, identificamos um total de trinta e duas orações referentes à pobreza. São elas: onze orações relacionais, sete orações materiais, seis orações comportamentais, cinco orações verbais, duas orações existenciais e uma oração mental. Predominam, portanto, as orações relacionais.

Em termos de participantes e circunstâncias, a pobreza e os termos do mesmo campo semântico integram essas orações como Ator (4 ocorrências) e Meta (3 ocorrências) em orações materiais; Identificador (3 ocorrências), Identificado (2 ocorrências), Portador (2 ocorrências) e Atributo (4 ocorrências) em orações relacionais; Verbiagem (5 ocorrências) em orações verbais; Fenômeno (1 ocorrência) em orações mentais; e Existente ( 2 ocorrências) em orações existenciais. Além disso, 'pobreza' desempenha o papel de Circunstância em 6 orações.

Dessa forma, também identificamos três representações distintas para a pobreza no jornal O Globo. Predominantemente, o veículo representa a pobreza como algo sobre o qual a sociedade age, já que em $50 \%$ dos papéis desempenhados por 'pobreza' em orações das notícias desse veículo são na forma de Meta, Identificador, Atributo, Verbiagem e Fenômeno. Com menos incidência (31\%), outra representação que identificamos foi a de que a pobreza é vista como uma entidade que pratica ações, que promove mudanças no mundo e que suas ações afetam intensamente a vida das pessoas, por integrar orações nas funções de Ator, Identificado, Portador e Existente. Além disso, verificamos que o jornal O Globo representa a pobreza como uma situação em que muitas pessoas vivem, sendo submetidas a condições de miserabilidade. Essa representação foi verificada ao constatarmos que a pobreza participa de $19 \%$ das orações como circunstância. A Tabela 7 apresenta exemplos dessas representações.

\section{Tabela 7 - Exemplos: jornal 0 Globo}

\begin{tabular}{|l|l|l|l|}
\hline Representação & Exemplo & & Notícia \\
\hline Objeto & Meta & $\begin{array}{l}\text { Para as Nações Unidas, a [pobreza] deve ser medida não apenas de } \\
\text { acordo com a renda, [...]. }\end{array}$ & OGlobo\#2 \\
\hline Entidade & Existente & No Brasil, há cerca de 29 milhões de [pobres] [...] . & OGlobo\#1 \\
\hline Situação & Circunstância & {$[\ldots] 43,6$ milhões vivendo na [pobreza]. } & OGlobo\#1 \\
\hline
\end{tabular}


5 A REPRESENTAÇÃO DA POBREZA PELA MÍDIA ON-LINE

Nas notícias analisadas, 'pobreza' integrou todos os tipos de orações na forma de diversos participantes. No que concerne às orações com o item lexical pobreza (e aqueles de mesmo campo semântico - pobre; pobres; taxa de empobrecimento; miséria; vulneráveis; nível de vulnerabilidade, de grande fragilidade), verificamos um total de cento e oitenta e três orações. O maior número de ocorrências identificado foi de orações relacionais, totalizando setenta e três $(40 \%)$. As orações relacionais são aquelas que identificam ou caracterizam seus participantes.

Em relação aos participantes e circunstâncias, destacou-se o número de orações em que a pobreza exercia o papel daqueles participantes que são afetados pelos processos, como Meta, Atributo, Identificador Verbiagem e Fenômeno. Essas ocorrências manifestaram-se em $51 \%$ das orações (94 ocorrências).

Encontramos, ainda, com menor incidência, orações em que a pobreza participa como uma entidade, pois adquire características tipicamente humanas ao ter a capacidade de realizar ações e também de atingir outras pessoas. Nessas ocorrências a pobreza exerce papéis de Ator, Portador, Identificado, Comportante e Existente. Registramos que esses participantes aparecem em $31 \%$ das orações.

Por fim, identificamos que em apenas $18 \%$ das orações 'pobreza' aparece como Circunstância. Nessas orações, é representada como uma situação em que os eventos se desenvolvem. A pobreza é uma circunstância, ou seja, é no estado de pobreza que as pessoas estão, agem e vivem. Os percentuais das ocorrências de cada uma das representações verificadas podem ser conferidos no Gráfico 1.

\section{Gráfico 1 - Representações para a pobreza pela mídia on-line}

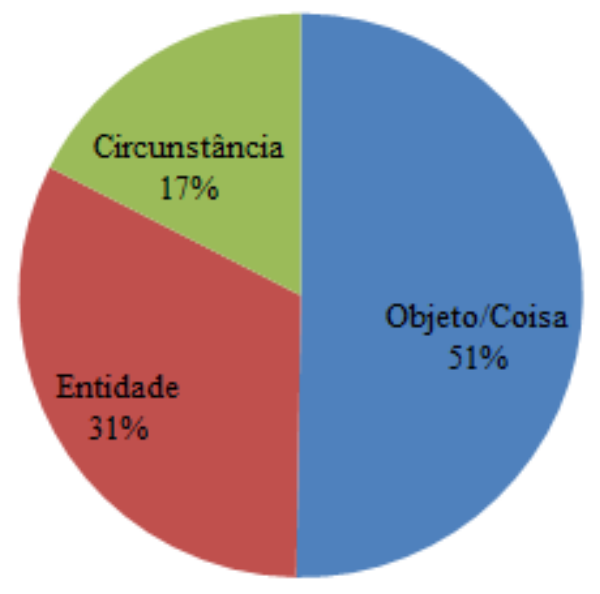

Dessa forma, identificamos três representações para a pobreza na mídia on-line. A mais recorrente é como um objeto, uma coisa que está suscetível às ações dos seres humanos, que pode ser afetada por aqueles que lutam contra ela, que buscam extinguila. Manifestando menos ocorrências, a pobreza é representada como uma entidade, um ser com características tipicamente humanas, que age e que provoca efeitos maléficos a outras pessoas. Por fim, a pobreza é representada como uma situação em que muitas pessoas se encontram, como uma precária condição em que muitos indivíduos vivem. 
Tendo em vista as três representações encontradas, podemos afirmar que a mídia, ao representar a pobreza, raramente a considera, por exemplo, algo decorrente das ações humanas. Percebemos, sim, que a pobreza é representada, mormente, como um mal que, definitivamente, deve ser eliminado, de modo que não é contemplada a responsabilidade que os indivíduos têm sobre a sua existência. Apesar de ser, na maior parte dos casos, o participante afetado, os participantes que agem sobre a pobreza não são apresentados como aqueles que a provocam, ou que contribuem para sua existência, mas como aqueles que têm a responsabilidade (por vezes a obrigação moral) de terminá-la.

Além disso, observamos que os jornais salientam muito os dados numéricos relacionados à pobreza, procurando classificar os indivíduos como pobres ou não, de acordo com a renda que recebem. Os periódicos jornalísticos parecem não procurar abordar a relação que existe entre pobreza e exclusão social (a propósito, em nenhuma das notícias este termo é mencionado). No entanto, entendemos que a pobreza não pode ser caracterizada apenas pelos aspectos econômicos (distribuição de renda), já que, conforme Eguía e Otarle (2007), ela se caracteriza como a carência de recursos que supram as necessidades básicas de um indivíduo, a baixa qualidade de vida, além da exclusão econômica e social. E tudo isso é reforçado pelas raras vezes em que a inclusão social é mencionada e, quando é, aparece como uma medida a ser tomada. Por fim, muito esporadicamente a pobreza foi comparada à riqueza, dando pouco espaço à abordagem da desigualdade social, comumente verificada no país e no mundo e diretamente relacionada à discrepância entre ricos e pobres.

\section{CONSIDERAÇÕES FINAIS}

Neste estudo, apresentamos uma discussão acerca da pobreza. Nosso objetivo principal foi analisar como se constituem as representações linguístico-discursivas da pobreza pela mídia on-line. Optamos por essa temática por considerarmos que a pobreza é um grave problema econômico e social, ao qual muitas pessoas são submetidas no mundo todo. Trata-se de uma preocupante questão social, algo inerente às nossas vidas, ao cotidiano de todos e, justamente por isso, não podemos deixar de abordar.

Para o desenvolvimento deste trabalho, atrelamos a Linguística SistêmicoFuncional (HALLIDAY; MATTHIESSEN, 2004), que considera a linguagem como um sistema sociossemiótico, à Análise Crítica do Discurso, abordagem teóricometodológica que utiliza a LSF para analisar a linguagem e mostrar como os discursos se materializam em textos e veiculam significados como a preocupação com a desigualdade social. Pudemos, a partir de um estudo qualitativo, analisando dez notícias de cinco renomados jornais brasileiros, obter resultados muito significativos em relação ao nosso objetivo.

Identificamos três representações distintas para a pobreza: como objeto à mercê das ações humanas, como uma entidade capaz de agir sobre outros seres e como uma situação a que muitos indivíduos são submetidos. Entendemos que o fato de a pobreza ser representada como um objeto sujeito às ações humanas (representação mais frequente no corpus) revela a luta constante da sociedade para erradicar esse mal. Isso é evidenciado pelos papéis léxico-gramaticais que 'pobreza' e termos de mesmo campo semântico exercem nas orações, nas funções de Verbiagem, Meta, Atributo, 
Identificado, Beneficiário e Fenômeno. A segunda representação mais frequente, como uma entidade, demonstra a capacidade que, infelizmente, a pobreza tem de atingir as pessoas, de afetar suas vidas, expondo-as a condições de miserabilidade. Essa representação é manifestada quando a pobreza e os termos de mesmo campo semântico integram orações nas funções de Ator, Portador, Identificado, Comportante e Existente. Por fim, a outra representação (com menos frequência) é a da pobreza enquanto uma situação em que muitas pessoas vivem; esses indivíduos carecem de recursos que suprem necessidades básicas e que permitem que se tenha uma vida com o mínimo de dignidade. Essa representação é evidenciada quando 'pobreza' integra orações no papel de circunstância.

Dessa forma, entendemos que a mídia on-line vê a pobreza justamente sob essas três perspectivas, diferentes, mas que se complementam. Para ela, a pobreza é um sério problema social, um mal que afeta a vida de muitas pessoas, submetendo-as a viverem de modo marginalizado, sendo expostas a problemas econômicos e sociais. A pobreza é, então, vista como uma situação desumana em que se encontra uma grande parcela da população mundial; ao mesmo tempo, a mídia parece entender que o objetivo principal da sociedade é exterminar a pobreza a fim de garantir qualidade de vida e dignidade a todos.

Acreditamos que este estudo, por investigar e discutir uma questão social, como é a pobreza, certamente tem relevância para os estudos linguísticos e sociais, especialmente para a Análise Crítica do Discurso, teoria que se interessa por questões relativas à desigualdade social. Entendemos a pobreza como o maior dos males que podem atingir uma nação e como uma consequência de sérios problemas econômicos. Muitos têm lutado para erradicá-la, pois a pobreza submete os indivíduos a um estado de penúria, vivendo em condições desumanas de miséria extrema, de carência de elementos que são essenciais para a sua sobrevivência, tais como saúde, educação, recursos financeiros e segurança.

\section{REFERÊNCIAS}

BAKHTIN, M. Estética da criação verbal. 4. ed. São Paulo: Martins Fontes, 2003.

BAZERMAN, C. Gêneros textuais, tipificação e interação. 2. ed. São Paulo: Cortez, 2006.

EGUÍA, A.; OTARLE, S. (Orgs.). Los significados de la pobreza. Buenos Aires: Biblos, 2007.

FAIRCLOUGH, N. Discurso e mudança social. Brasília: UnB, 2001.

FUZER, C.; CABRAL, S. R. S. (Orgs.). Introdução à Gramática Sistêmico-Funcional em Língua Portuguesa. Santa Maria: UFSM, 2010.

HALliDAY, M. A. K.; MATTHIESSEN, C. M. I. M. An Introduction to functional grammar. 3. ed. London: Hodder Education, 2004.

LAGE, N. Estrutura da notícia. 5. ed. São Paulo: Ática, 2002.

MARCUSCHI, L. A. Gêneros textuais: definição e funcionalidade. In: DIONÍSIO, A. P.; MACHADO, A. R.; BEZERRA, M. A. (Orgs.). Gêneros textuais e ensino. 3. ed. Rio de Janeiro: Lucerna, 2005. Produção textual, análise de gêneros e compreensão. São Paulo: Parábola Editorial, 2008.

PEDRO, E. (Org.). Análise Crítica do Discurso: Uma perspectiva sociopolítica e funcional. Lisboa: Editorial Caminho, 1997.

THOMPSON, G. Introducing Functional Grammar. 2. ed. Arnold: London, 2004.

VAN DIJK, T. A. Discurso, notícia e ideologia. Estudos na Análise Crítica do Discurso. Porto: Campo das Letras, 2005. 
WODAK, R. Do que trata a ACD? Um resumo de sua história, conceitos importantes e seus desenvolvimentos. Linguagem em (Dis)curso, v. 4, n. esp: "Análise Crítica do Discurso", org. por Carmen Rosa Caldas-Coulthard e Débora de Carvalho Figueiredo, p. 223-243, 2004.

\section{REFERÊNCIAS DO CORPUS}

CORREIO DO POVO. Em cinco anos, 10 milhões de pessoas deixam a pobreza no Brasil. Disponível em: <http://www.correiodopovo.com.br/Noticias/?Noticia=338357>. Acesso em: 15 set. 2011.

Pobreza no Brasil tem face negra e feminina, diz Dilma. Disponível em:

<http://www.correiodopovo.com.br/Noticias/?Noticia=362350>. Acesso em: 19 nov. 2011.

FOLHA DE S.PAULO. Brasil vai enfrentar pobreza com determinação, ressalta Dilma. Disponível em: $<$ http://www1.folha.uol.com.br/multimidia/podcasts/925858-brasil-vai-enfrentar-pobreza-comdeterminacao-ressalta-dilma.shtml>. Acesso: 06 jun. 2011.

Número de pobres na França salta para 8,2 milhões de pessoas. Disponível em:

$\overline{<\mathrm{http}: / / w w w 1 . f o l h a . u o l . c o m . b r / m u n d o / 967381-n u m e r o-d e-p o b r e s-n a-f r a n c a-s a l t a-p a r a-82-m i l h o e s-d e-~}$ pessoas.shtml>. Acesso em: 30 ago. 2011.

O ESTADO DE S.PAULO. Pobreza extrema atinge 1 em cada 15 pessoas nos EUA. Disponível em: $<$ http://www.estadao.com.br/noticias/internacional,pobreza-extrema-atinge-1-em-cada-15-pessoas-noseua,794192,0.htm>. Acesso em: 03 nov. 2011.

Quase um terço das crianças dos EUA são pobres, aponta Censo. Disponível em:

$<$ http://www.estadao.com.br/noticias/internacional,quase-um-terco-das-criancas-dos-eua-sao-pobresaponta-censo,799730,0.htm>. Acesso em: 17 nov. 2011.

O GLOBO. Número de americanos vivendo abaixo da linha de pobreza bate recorde. Disponível em: $<$ http://oglobo.globo.com/economia/numero-de-americanos-vivendo-abaixo-da-linha-de-pobreza-baterecorde-2700013>. Acesso em: 13 set. 2011.

Brasil tem 5 milhões de pessoas em situação de pobreza. Disponível em:

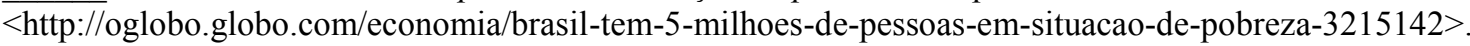
Acesso em: 02 nov. 2011.

ZERO HORA. RS tem mais de 300 mil pessoas vivendo na extrema pobreza. Disponível em: $<$ http://zerohora.clicrbs.com.br/rs/economia/noticia/2011/05/rs-tem-mais-de-300-mil-pessoas-vivendona-extrema-pobreza-3296409.html>. Acesso em: 03 maio 2011.

Número de pessoas abaixo da linha pobreza nos EUA bate recorde ao passar de 46 milhões. Disponível em: <http://zerohora.clicrbs.com.br/rs/economia/noticia/2011/09/numero-de-pessoas-abaixoda-linha-pobreza-nos-eua-bate-recorde-ao-passar-de-46-milhoes-3485787.html>. Acesso em: 13 set. 2011.

Recebido em: 24/07/13. Aprovado em: 15/06/14.

Title: Representation of poverty by the on-line media

Authors: Valeria Iensen Bortoluzzi; Glivia Guimarães Nunes

Abstract: The subject in this study is the linguistic-discursive representation of poverty by online media. The theoretical and methodological support used is that of Critical Discourse Analysis (FAIRCLOUGH, 2001) and the transitivity system of the Systemic Functional Grammar (HALLIDAY; MATTHIESSEN, 2004). The corpus comprises ten stories published between May and November 2011 in online editions of renowned Brazilian newspapers: Zero Hora, Correio do Povo, O Globo, O Estado de São Paulo and Folha de São Paulo. Two news were selected from each newspaper and submitted to a qualitative, interpretative analysis. Initially, how each newspaper represents poverty was identified, and then it was observed how online media represents poverty. We found three representations for poverty: as an object susceptible to human action, as an entity that acts on individuals, and as a situation faced by many people.

Keywords: Text. Discourse. Online Media. Representation. Poverty. 
Título: Representación de la pobreza por los medios de comunicación en línea Autores: Valeria Iensen Bortoluzzi; Glivia Guimarães Nunes

Resumen: El tema de este estudio es la representación lingüístico-discursiva de la pobreza por los medios de comunicación el línea. El trabajo tiene el apoyo teórico y metodológico del Análisis Crítico del Discurso (FAIRCLOUGH, 2001), y el aporte teórico del sistema de transitividad de la Gramática Sistémico-Funcional (HALLIDAY; MATTHIESSEN, 2004). El corpus fue constituido de diez noticias publicadas entre los meses de mayo y noviembre de 2011, en ediciones en línea de reconocidos periódicos brasileños: Zero Hora, Correio do Povo, O Globo, O Estado de S. Paulo y Folha de S. Paulo. Seleccionamos dos noticias de cada periódico y realizamos un análisis cualitativo e interpretativo. Inicialmente, identificamos como cada uno de los periódicos representa la pobreza para, luego después, observar qué representación los medios de comunicación en línea tiene acerca de la pobreza. Verificamos la existencia de tres representaciones para la pobreza: como un objeto a merced de las acciones humanas, como una entidad que actúa sobre los individuos y como una situación enfrentada por muchas personas.

Palabras-clave: Texto. Discurso. Medios de comunicación en línea. Representación. Pobreza. 